Article

\title{
(9R)-9-Hydroxystearate-Functionalized Anticancer Ceramics Promote Loading of Silver Nanoparticles
}

\author{
Elisa Boanini ${ }^{1, *(\mathbb{D})}$, Maria Cristina Cassani ${ }^{2}$ (D) Katia Rubini $^{1}$, Carla Boga ${ }^{2}$ (D) and \\ Adriana Bigi ${ }^{1, *}$ (D) \\ 1 Department of Chemistry “Giacomo Ciamician”, University of Bologna, via Selmi, 2, 40126 Bologna, Italy; \\ katia.rubini@unibo.it \\ 2 Department of Industrial Chemistry “Toso Montanari”, Via del Risorgimento, 4, 40136 Bologna, Italy; \\ maria.cassani@unibo.it (M.C.C.); carla.boga@unibo.it (C.B.) \\ * Correspondence: elisa.boanini@unibo.it (E.B.); adriana.bigi@unibo.it (A.B.); Tel.: +39-051-2099551 (A.B.)
}

Received: 3 May 2018; Accepted: 29 May 2018; Published: 31 May 2018

\begin{abstract}
Functionalization of calcium phosphates for biomedical applications has been proposed as a strategy to enrich the good osteoinductive properties of these materials with specific therapeutic characteristics. Herein, we prepared and characterized hydroxyapatite nanocrystals functionalized with an anticancer agent, (9R)-9-hydroxystearate (HSA), and loaded with an antimicrobial agent, namely silver nanoparticles (AgNPs). Nanocrystals at two different contents of HSA, about 4 and $9 \mathrm{wt} \%$, were prepared via direct synthesis in aqueous solution. Loading with the antibacterial agent was achieved through interaction with different volumes of AgNPs suspensions. The amount of loaded nanoparticles increases with the volume of the AgNPs suspension and with the hydroxystearate content of the nanocrystals, up to about $3.3 \mathrm{wt} \%$. The structural, morphological, and hydrophobic properties of the composite materials depend on hydroxystearate content, whereas they are not affected by AgNPs loading. At variance, the values of zeta potential slightly increase with the content of AgNPs, which exhibit a sustained release in cell culture medium.
\end{abstract}

Keywords: hydroxyapatite; silver; nanoparticles; X-ray diffraction; transmission electron microscopy; ceramic; biomaterial

\section{Introduction}

Calcium phosphate $(\mathrm{CaP})$-based biomaterials are among the most utilized systems in biomedical applications aimed to solve problems related to musculoskeletal disorders. In particular, hydroxyapatite (HA) closely resembles the inorganic phase of bone and is the most employed CaP for hard tissue substitution/repair. HA displays an extremely good biocompatibility and bioactivity, and it can be utilized as delivery system of active agents aimed to promote specific biological functions [1]. To this purpose, HA can be functionalized with bioactive ions, molecules, growth factors, and drugs, adding specific characteristics to the osteogenic properties of the calcium phosphate [2-7]. We have previously synthesized HA at different contents of (9R)-9-hydroxystearate (HSA) [8]. HSA derives from 9-hydroxystearic acid, an endogenous long-chain monohydroxyl fatty acid, which is able to downregulate tumor cell proliferation [9]. In fact, it was shown to provoke apoptosis of the osteosarcoma cell line U2OS via a mitochondrial pathway [10]. Moreover, especially in the $(9 R)$ enantiomeric form, it exerts an antiproliferative action on the colon cancer cell line HT29 [11]. HSA maintains its antitumor activity also when incorporated into HA, in agreement with the cytostatic and cytotoxic effect of HSA functionalized HA nanocrystals on osteosarcoma cell line SaOS2, which is modulated by HSA content of the composite material [9].

Herein, we explored the possibility to add a further functionalization to hydroxystearate containing HA nanocrystals through loading of silver nanoparticles (AgNPs). AgNPs should imbue 
antimicrobial properties to the functionalized nanocrystals, in agreement with their strong efficacy as broad-spectrum antibacterial agents [12,13]. As a matter of fact, AgNPs are widely employed as antibacterial agents in the biomedical field, as well as in several other applications, including water disinfection and cosmetics [14]. Their main applications in the biomedical field include wound dressing, catheters, and cardiovascular implants [15]. More recently, AgNPs have been raising increasing interest also for orthopedic applications [4,16-18]. In this study we synthesized hydroxyapatite nanocrystals at different hydroxystearate and AgNPs contents. To this aim, we loaded different amounts of AgNPs stabilized with low molecular weight polyethylenimine (PEI) on hydroxyapatite synthesized at different hydroxystearate contents. The results indicate that hydroxystearate functionalization influences AgNPs loading, which reaches contents up to about $3.3 \mathrm{wt} \%$ in the samples at the highest hydroxystearate content.

\section{Materials and Methods}

\subsection{Synthesis of Composite Materials}

Hydroxyapatite was synthesized by a co-precipitation method, using $\mathrm{CO}_{2}$-free distilled water and under $\mathrm{N}_{2}$ atmosphere in order to avoid the formation of carbonated apatite. Fifty milliliters of $\mathrm{Ca}\left(\mathrm{NO}_{3}\right)_{2} \cdot 4 \mathrm{H}_{2} \mathrm{O}$ solution $(1.08 \mathrm{M}), \mathrm{pH} 10$ adjusted with ammonia, was added drop-wise to $50 \mathrm{~mL}$ of $\left(\mathrm{NH}_{4}\right)_{2} \mathrm{HPO}_{4} 0.65 \mathrm{M}$ solution at $90{ }^{\circ} \mathrm{C}$ under stirring. The reaction solution was kept at $90{ }^{\circ} \mathrm{C}$ for $5 \mathrm{~h}$ under stirring, and then the precipitate was separated by centrifugation at 10,000 rpm for $10 \mathrm{~min}$, rinsed twice with $\mathrm{CO}_{2}$-free distilled water, and dried at $37^{\circ} \mathrm{C}$.

Potassium (9R)-9-hydroxystearate was prepared by treatment of (9R)-9-hydroxystearic acid, obtained from Dimorphotheca sinuata L. seed oil [11], with an equimolar amount of $\mathrm{KOH}$ in methanol solution, as previously described [8]. Samples containing HSA were obtained following the above procedure but dissolving potassium (9R)-9-hydroxystearate into the $\left(\mathrm{NH}_{4}\right)_{2} \mathrm{HPO}_{4}$ solution before starting dropping the $\mathrm{Ca}\left(\mathrm{NO}_{3}\right)_{2} \cdot 4 \mathrm{H}_{2} \mathrm{O}$ solution. The concentrations of potassium (9R)-9-hydroxystearate used were 10 and $20 \mathrm{mM}$, calculated on final volume. The obtained powder samples were labelled as HSA10 and HSA20, respectively.

Silver nanoparticles (AgNPs) solution was prepared by heating $100 \mathrm{ml}$ of $\mathrm{AgNO}_{3}$ solution $(10 \mathrm{mM}$ in ultra-pure MilliQ water) until $100{ }^{\circ} \mathrm{C}$ under stirring. When the solution is boiling, $0.70 \mathrm{~mL} 10 \%$ $(w / w)$ of polyethyleneimine (PEI) (average $\mathrm{M}_{\mathrm{w}} \sim 2000,50 \mathrm{wt} \%$ in $\mathrm{H}_{2} \mathrm{O}$, Sigma-Aldrich, St. Louis, $\mathrm{MO}$, USA) solution was added quickly in one step. The solution was vigorously stirred for 4 min and then cooled at room temperature. Finally, the volume was taken back to $100 \mathrm{~mL}$ with ultra-pure water in order to compensate for evaporation.

In order to support AgNPs on apatitic materials, different volumes of AgNPs solution were added to $0.5 \mathrm{~g}$ of powder (HA, HSA10, and HSA20). Each support was submitted to incubation with 5, 20, and $50 \mathrm{~mL}$ of solution. The suspension was vigorously stirred for $1 \mathrm{~h}$ at room temperature. The product is then filtered and dried at $37^{\circ} \mathrm{C}$. Final materials were labeled using a combination indicating the kind of apatitic support and the volume of AgNPs solution (i.e., HA-Ag5 indicates the sample obtained after incubation of HA into $5 \mathrm{~mL}$ of AgNPs solution; HSA20-Ag50 indicates the sample obtained after incubation of HSA20 into $50 \mathrm{~mL}$ of AgNPs solution).

\subsection{Characterization of Composite Materials}

X-ray diffraction analysis was performed using a PANalytical X'Pert PRO powder diffractometer (Malvern PANalytical, Almelo, The Netherlands) equipped with a fast $X^{\prime}$ Celerator detector. $\mathrm{CuK} \alpha$ radiation was used $(40 \mathrm{~mA}, 40 \mathrm{kV})$. The patterns were recorded in the $10^{\circ}-60^{\circ} 2 \theta$ range with a step size of $0.1^{\circ}$ and time/step of $100 \mathrm{~s}$. In order to evaluate the coherence lengths of the crystals and to perform the full profile pattern refinement, further $\mathrm{X}$-ray powder data were collected with a fixed counting time of $400 \mathrm{~s}$ for each $0.033 / \mathrm{step}$, using silicon as internal standard. The Scherrer formula [19] was applied to calculate the coherence lengths of crystalline domains. The Rietveld 
routine of the HighScore Plus software package (Malvern PANalytical, Almelo, The Netherlands)) was used to process the data for evaluation of cell parameters.

HSA content was determined through thermogravimetric analysis using a Perkin-Elmer TGA-7. Heating was performed in a platinum crucible in air flow $\left(20 \mathrm{~cm}^{3} / \mathrm{min}\right)$ at a rate of $10^{\circ} \mathrm{C} / \mathrm{min}$ up to $900{ }^{\circ} \mathrm{C}$. The samples' weights were in the range $5-10 \mathrm{mg}$.

The amount of silver present in the different samples was determined by atomic absorption spectroscopy (AAS, Thermo Scientific, Waltham, MA, USA) in air-acetylene flame $(\lambda=328.1 \mathrm{~nm}$; spectral band-width $=0.5 \mathrm{~nm}$ ). Ca. $8 \mathrm{mg}$ of previously grinded solid samples were solubilized in $25 \mathrm{~mL}$ of a $0.5 \mathrm{M} \mathrm{HNO}_{3}$ aqueous solution. The calibration line was made with 5 calibration standards $(2,4,6,8,10 \mathrm{ppm})$, prepared by dilution to $50 \mathrm{~mL}$ of a $100 \mathrm{ppm}$ silver standard for AAS in $0.5 \mathrm{M} \mathrm{HNO}_{3}$ (Merck KGaA , Darmstadt, Germany).

A Philips CM100 transmission electron microscope $(80 \mathrm{kV})$ was used for TEM investigations. Sample powders were suspended in ethanol and sonicated. A drop of sonicated suspension was transferred onto formvar films supported on conventional copper microgrids. The Image $J^{\circledR}$ picture analyzer software was used to estimate the mean particles dimensions. The reported results are the average values of measurements performed over at least 100 data points per sample.

Zeta potential was measured using Electrophoretic Light Scattering (ZetasizerNano; Malvern PANalytical, Malvern, UK). Five milligrams of powder sample were suspended in $50 \mathrm{~mL}$ of MilliQ water after sonication for $2 \mathrm{~min}$. Each analysis was performed in triplicate.

Atomic force Microscopy (AFM), contact angle and silver release analyses were carried out on disk-shaped samples $(\varnothing=6.0 \mathrm{~mm}$ ) in order to examine the materials mimicking the conditions of possible applications as biomaterials. Disk-shaped samples were prepared by pressing the powder (40 mg for each disk) into cylindrical molds by using a standard evacuable pellet die (Hellma, Müllheim, Germany).

Static contact angle measurements were performed by means of a Theta Lite optical tensiometer (Biolin Scientific, Gothenburg, Sweden) under ambient conditions by recording the side profiles of deionized water drops for image analysis. The shape of the drop was recorded in a time range of 0-30 s, with images collected every $0.033 \mathrm{~s}$. At least five drops were observed for each sample.

AFM imaging was performed using a Veeco Nanoscope 3D instrument (Veeco, Plainview, NY, USA). The disk-shaped samples were analyzed in tapping mode using an E scanner (maximum scan size $15 \mu \mathrm{m}$ ) and phosphorus (n) doped silicon probes (spring constant $20-80 \mathrm{~N} / \mathrm{m}$; resonance frequency $250-290 \mathrm{kHz}$; nominal tip radius $<10 \mathrm{~nm}$ ). Roughness parameters, namely arithmetic mean roughness (Ra), root-square roughness $(\mathrm{Rq})$, and the vertical distance between the highest and lowest points within the evaluation length $(\mathrm{Rt})$, were recorded.

Release of silver from disk-shaped samples was measured in the medium used for cell culture differentiation, Dulbecco's Modified Eagle Medium (DMEM, Sigma, Saint Louis, MO, USA) supplemented with antibiotics (100 U/mL penicillin, $100 \mu \mathrm{g} / \mathrm{mL}$ streptomycin). Ag content in the supernatant was analyzed at increasing times up to 14 days using flame atomic absorption spectroscopy (AAS, Thermo Scientific, Waltham, MA, USA), in air-acetylene flame $(\lambda=328.1 \mathrm{~nm}$; spectral band-width $=0.5 \mathrm{~nm}$ ). Results from this analysis represent the mean value of three different determinations.

\section{Results and Discussion}

The XRD patterns of the different supports functionalized with AgNPs show a number of reflections, which correspond to those characteristic of hydroxyapatite (PDF 9-432), together with the most intense reflection of $\mathrm{Ag}$ at about $38.1^{\circ}$ of $2 \theta$ (PDF 4-873). The relative intensity of this peak increases on passing from HA-Ag50 to HSA10-Ag50, to HSA20-Ag50 (Figure 1a) and as the volume of the AgNPs colloidal suspension increases (Figure 1b), suggesting the presence of variable quantities of metallic silver associated to the different materials as a function of experimental procedures.

Functionalization does not affect significantly the dimensions of the unit cell of the apatitic structure, as shown by the values of the lattice parameters of the different samples reported in 
Table 1. The comparison between the XRD patterns reported in Figure 1a shows that the patterns of the samples functionalized with HSA display slightly broader diffraction reflections than those of HA-Ag50, in agreement with an overall reduction of the length of crystallite sizes ( $\tau_{\text {hkl }}$ ) provoked by HSA functionalization [8]. The values of the mean crystallite sizes along the $c$-axis $\left(\tau_{002}\right)$ and along a direction perpendicular to it $\left(\tau_{310}\right)$, calculated using the Scherrer equation [19] and reported in Table 1 , display an anisotropic reduction on increasing HSA content. The greater reduction along the direction perpendicular to the $c$-axis suggests that hydroxystearate is preferentially adsorbed on HA (hk0) faces, as previously reported for anionic polyelectrolytes and acidic amino acids $[8,20,21]$.
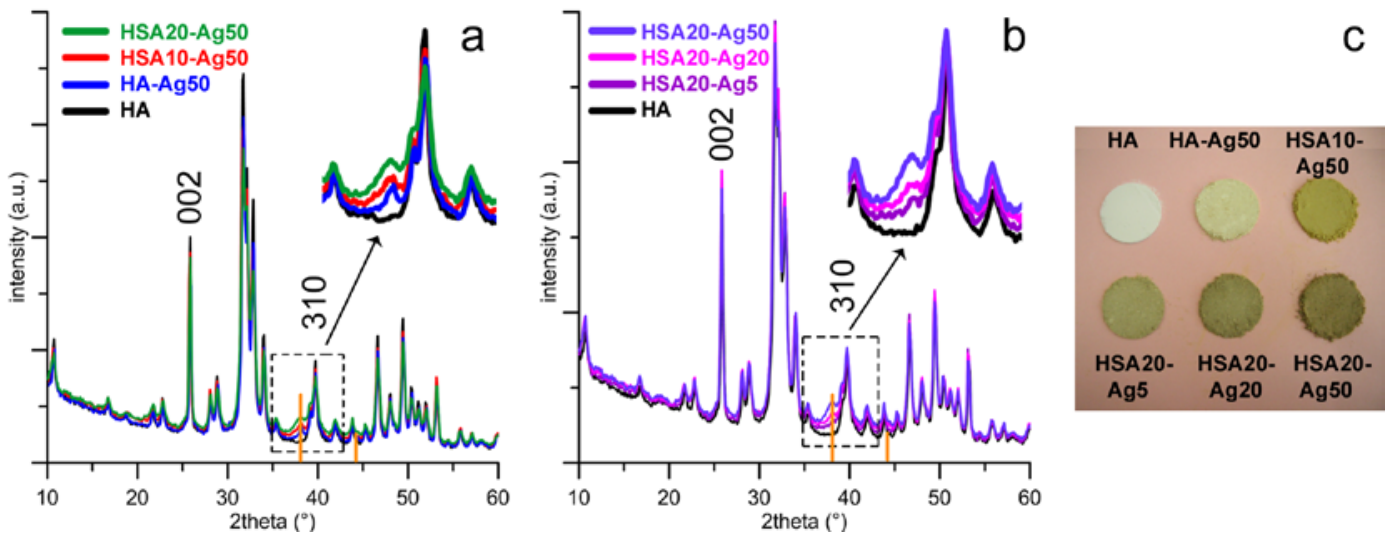

Figure 1. X-ray diffraction patterns of materials functionalized with silver nanoparticles (AgNPs): (a) different supports loaded in $50 \mathrm{~mL}$ of AgNPs suspension; (b) HSA20 loaded in different volumes of AgNPs; (c) photographs of samples. The samples are labelled HA-AgX and HSAY-AgX, where X indicates the volume (in $\mathrm{mL}$ ) of the AgNPs suspension used for loading, and $\mathrm{Y}$ is the hydroxystearate concentration (in $\mathrm{mM}$ ) in the synthesis solution. The positions of the 002 and 310 peaks of HA used for the evaluation of the crystallite size are indicated. The two orange bars indicate the positions of the two most intense reflections of silver metal (PDF 4-873).

Table 1. Structural parameters, silver content and surface parameters of composite materials. Standard deviations are reported in parentheses.

\begin{tabular}{cccccccc}
\hline Sample & $\mathbf{a}(\AA)$ & $\mathbf{c}(\AA)$ & $\boldsymbol{\tau}_{\mathbf{0 0 2}}(\AA \mathbf{\AA})$ & $\boldsymbol{\tau}_{\mathbf{3 1 0}}(\mathbf{\AA})$ & $\begin{array}{c}\text { Ag Content } \\
(\mathbf{w t} \mathbf{\%})\end{array}$ & $\begin{array}{c}\zeta \text { Potential } \\
(\mathbf{m} \mathbf{)})\end{array}$ & $\begin{array}{c}\text { Contact } \\
\text { Angle }\left({ }^{\circ}\right)\end{array}$ \\
\hline HA & $9.423(2)$ & $6.883(2)$ & $523(7)$ & $315(4)$ & - & -8.5 & $10(4)$ \\
HA-Ag5 & $9.427(2)$ & $6.883(2)$ & $518(5)$ & $308(3)$ & $0.5(1)$ & +0.5 & $20(5)$ \\
HA-Ag20 & $9.421(1)$ & $6.879(1)$ & $522(6)$ & $316(4)$ & $1.0(1)$ & +7.2 & $18(2)$ \\
HA-Ag50 & $9.427(2)$ & $6.886(3)$ & $515(6)$ & $304(3)$ & $1.2(1)$ & +8.3 & $25(2)$ \\
HSA10-Ag5 & $9.428(3)$ & $6.878(3)$ & $473(5)$ & $212(3)$ & $0.6(1)$ & -2.6 & $113(2)$ \\
HSA10-Ag20 & $9.430(2)$ & $6.884(2)$ & $478(5)$ & $208(2)$ & $2.2(1)$ & +3.5 & $119(1)$ \\
HSA10-Ag50 & $9.414(2)$ & $6.871(2)$ & $471(4)$ & $200(3)$ & $2.9(1)$ & +5.0 & $114(3)$ \\
HSA20-Ag5 & $9.431(3)$ & $6.879(3)$ & $450(5)$ & $172(2)$ & $0.8(1)$ & -5.0 & $123(5)$ \\
HSA20-Ag20 & $9.414(2)$ & $6.871(3)$ & $458(4)$ & $176(2)$ & $2.4(1)$ & +1.2 & $128(3)$ \\
HSA20-Ag50 & $9.430(2)$ & $6.880(2)$ & $453(4)$ & $171(1)$ & $3.3(1)$ & +2.0 & $121(2)$ \\
\hline
\end{tabular}

Quantitative chemical analysis confirms that AgNP loading depends both on the different supports and on the amount of AgNPs suspension used for the loading procedure: as shown in Table 1, the maximum amount loaded on $\mathrm{HA}$ is about $1.2 \%$, whereas it reaches values up to $3.3 \%$ on HSA containing supports. The maximum AgNPs loading achieved on HSA samples is smaller than that previously loaded on polyacrylate functionalized HA supports [22]. However, previous data demonstrated that contents greater than 3\% provoke significant cytotoxicity, whereas lower values imbue the materials with a long standing antibacterial activity without causing cytotoxicity [22]. The different amounts of AgNPs loaded on the different substrates are confirmed by the different 
number of nanoparticles appreciable in the TEM images of the different samples. The images reported in Figure 2a-c allow to appreciate a significantly higher number of AgNPs on HSA containing samples than on HA nanocrystals. Furthermore, electron microscopy allows to verify that AgNPs are always associated to the surface of the apatitic crystals. In fact, free particles are never observed. The average diameter of the nanoparticles, about $7 \mathrm{~nm}$, as well as their size distribution, does not vary significantly on the different supports (Figure $2 \mathrm{~d}-\mathrm{f}$ ).
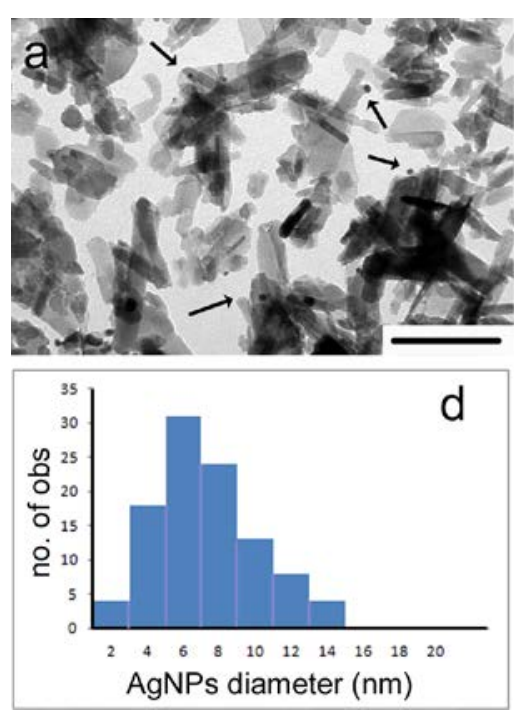
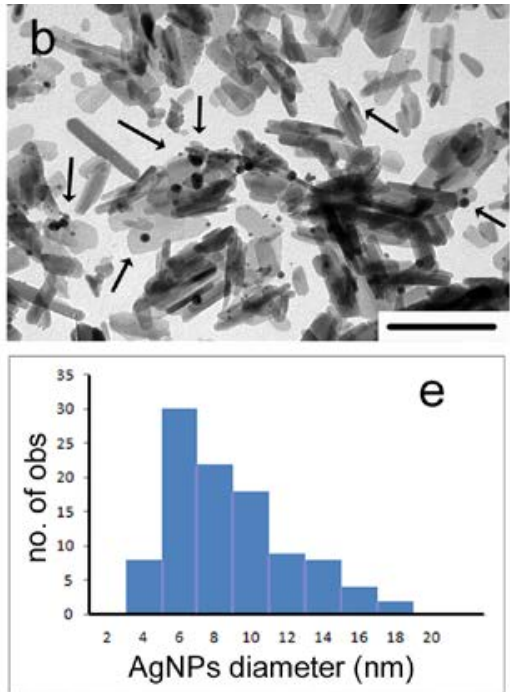
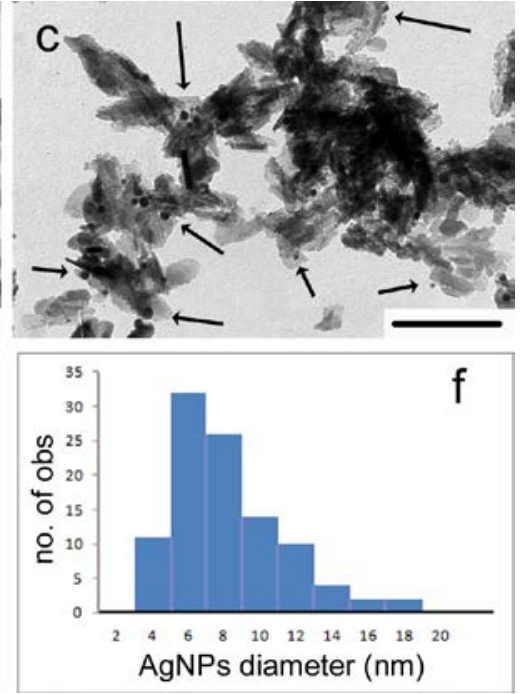

Figure 2. Transmission electron microscopy images of materials functionalized with AgNPs and related AgNPs size distribution diagrams: (a,d) HA-Ag50; (b,e) HSA10-Ag50 and (c,f) HSA20-Ag50. The arrows in micrographs indicate AgNPs. Bars $=200 \mathrm{~nm}$.

A qualitative evaluation of AgNPs presence is provided also by the color variation of the different supports which can be observed on increasing AgNPs loading (Figure 1c). The presence of silver provides the powders with a yellow-brownish color, which is more intense for HSA functionalized samples and becomes darker on increasing AgNPs content. The great AgNPs amounts loaded onto HSA-containing supports in comparison to HA support can be related to the more negatively charged surfaces of the functionalized crystals, which exert a greater attraction towards the PEI-stabilized AgNPs. Indeed, HSA10 and HSA20 exhibit more negative values of zeta potential than HA. Furthermore, adsorption of the positively charged nanoparticles (zeta potential of AgNPs $=+37 \mathrm{mV}[22,23]$ ) provokes an increase of the zeta potential of all the samples, as shown in Table 1.

AgNPs adsorption does not provoke any significant variation of the content of HSA of the different samples, as determined through thermogravimetric analysis. Thermal decomposition of hydroxystearate occurs between 200 and $600{ }^{\circ} \mathrm{C}$ and the total weight loss calculated from the thermogravimetric plots of the different samples indicates that HSA content assumes mean values of about 4 and $9 \%$ respectively in HSA10 and HSA20 samples, independently from the presence of AgNPs. Typical thermogravimetric plots are reported in Figure 3 for samples loaded with Ag50. The slightly different weight losses (about $1 \mathrm{wt} \%$ ) exhibited by HA-Ag50 and HA, which has been reported for comparison, are due to the adsorption of PEI from the AgNPs suspension onto HA-Ag50 nanocrystals. 


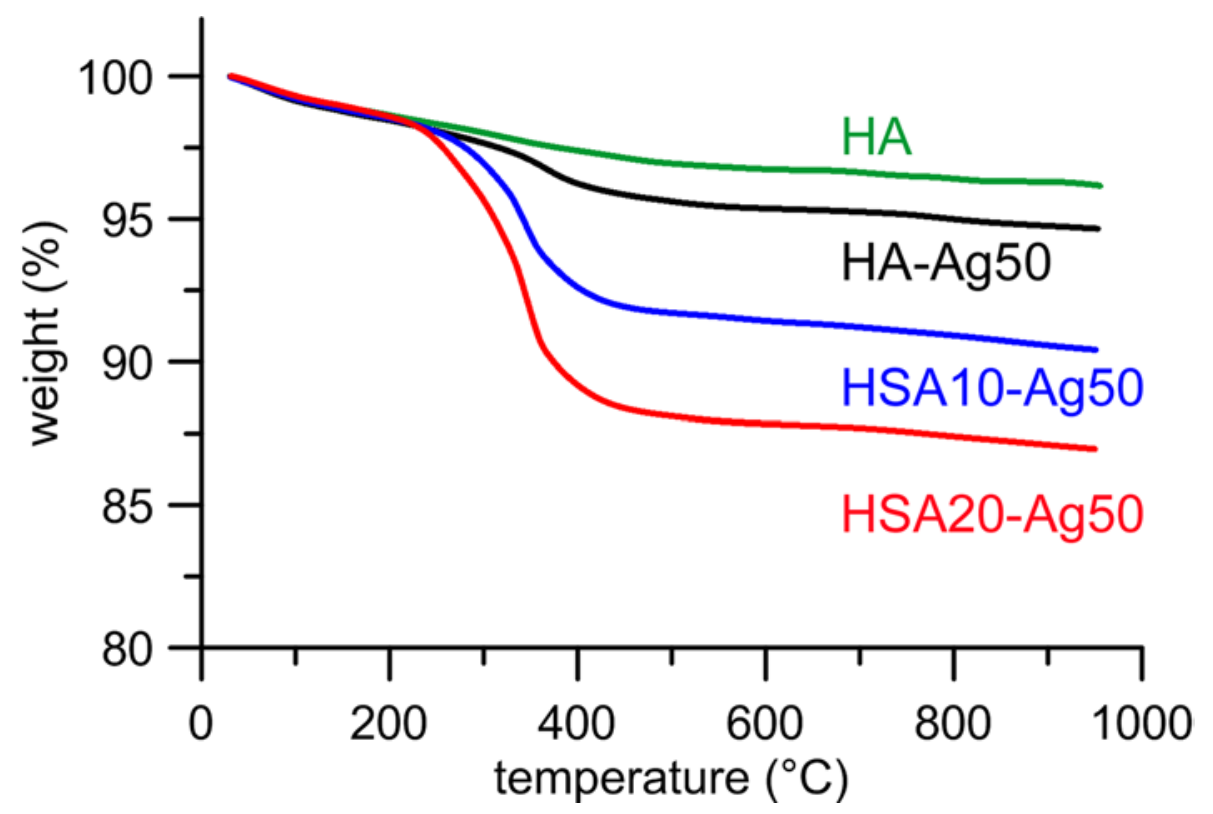

Figure 3. Thermogravimetric plots of as-prepared HA, HA-Ag50, HSA10-Ag50, and HSA20-Ag50, useful for quantification of HSA in the composite materials.

HSA hydrophobic tails on the nanocrystals surface are also responsible for the very great difference between the values of contact angle measured on HSA containing samples than on the HA ones (Table 1). The values are slightly higher for HSA20 than for HSA10 samples, in agreement with their different hydroxystearate content, and do not vary during the $30 \mathrm{~s}$ of acquisition. At variance, the water droplet is completely spread on HA samples within a few seconds (Figure 4). The data reported in Table 1 show that the hydrophobic/hydrophilic behavior of the samples was not significantly modified by the presence of AgNPs.

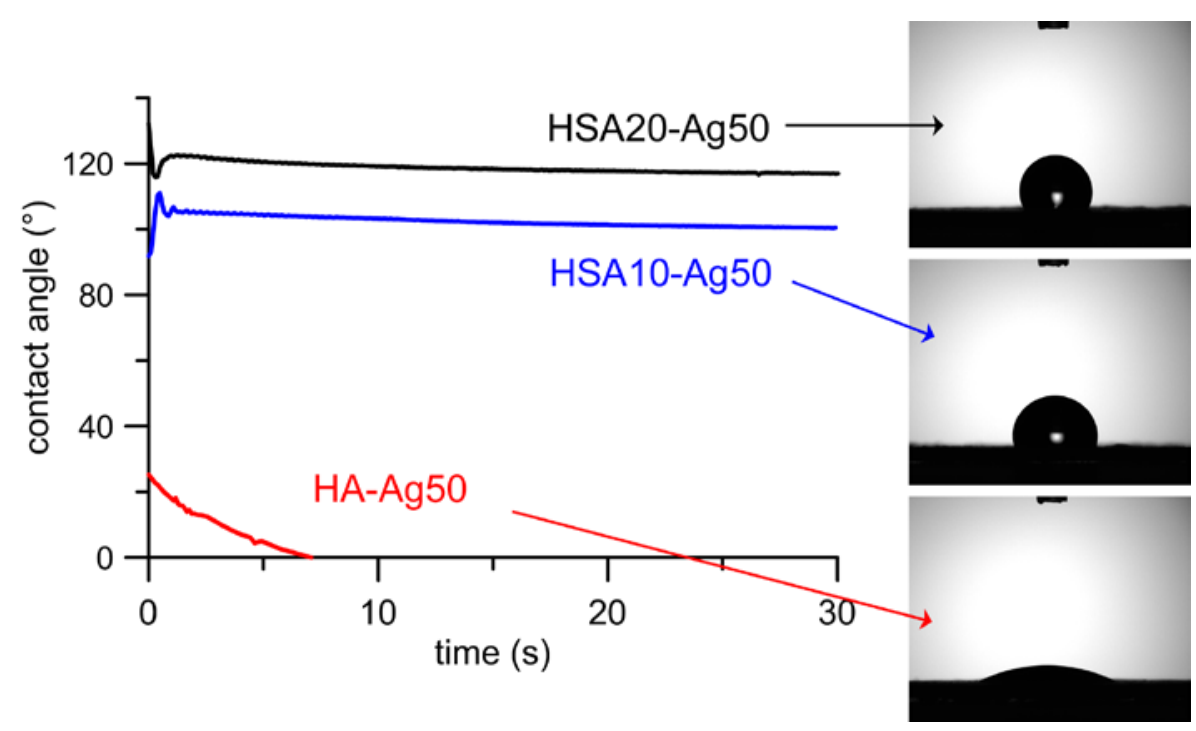

Figure 4. Plots of contact angle values as a function of time. The images of droplets measured after 1 second on different composite materials are shown on the right.

Contact angle measurements, as well as AFM investigation and release analysis, were performed on disk-shaped samples in order to mimic the conditions of possible applications as biomaterials. 
Indeed, the nanometric dimensions of the synthesized materials can cause severe cytotoxic effects and prevent their use as free powders [24]. The results of AFM investigation indicate a decrease of the roughness parameters, $\mathrm{Ra}, \mathrm{Rq}$ and $\mathrm{Rt}$, on passing from HA to HSA containing samples, most likely because of the smaller dimensions of these last nanocrystals, as it can be appreciated also in Figure 2. The average values do not vary significantly as a function of AgNPs content and are: $\mathrm{Ra}=0.060 \pm 0.004 \mu \mathrm{m}, \mathrm{Rq}=0.075 \pm 0.002 \mu \mathrm{m}, \mathrm{Rt}=0.495 \pm 0.015 \mu \mathrm{m}$ for HA and $\mathrm{Ra}=0.024 \pm 0.002 \mu \mathrm{m}, \mathrm{Rq}=0.030 \pm 0.003 \mu \mathrm{m}, \mathrm{Rt}=0.247 \pm 0.012 \mu \mathrm{m}$ for HAHSA20 samples, independently from their AgNPs content. The images of two typical samples are reported in Figure 5.
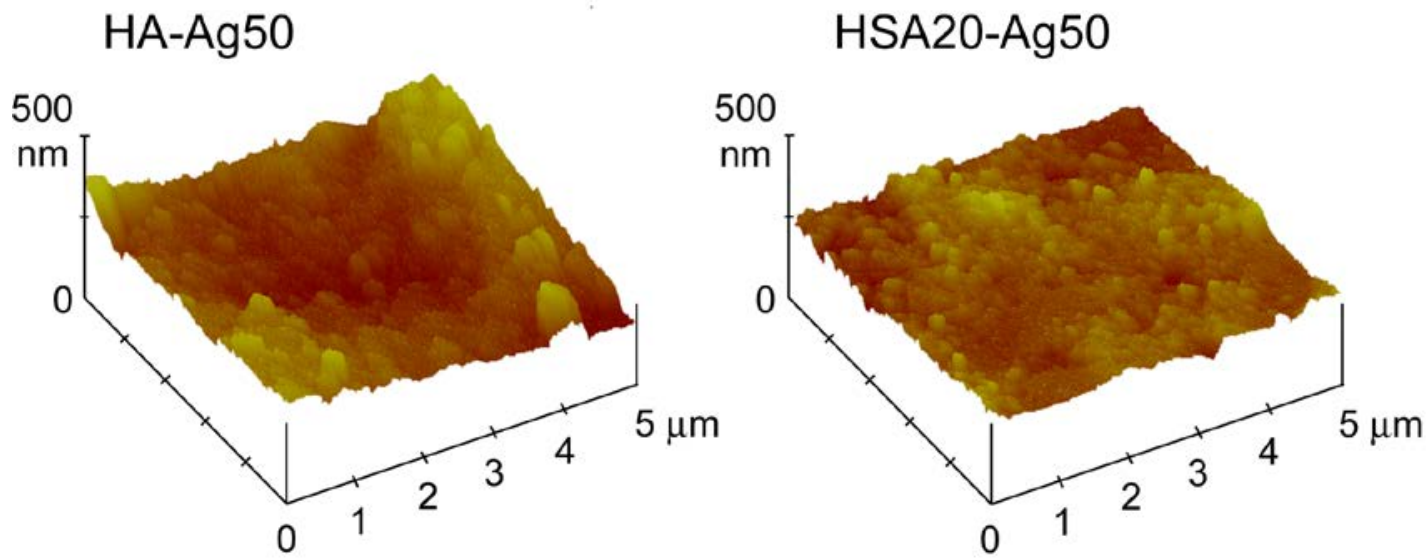

Figure 5. Atomic force microscopy images of the surfaces of disk-shaped samples obtained by pressing as-prepared HA-Ag50 and HSA20-Ag50 powders into cylindrical molds.

Ag release from HA-Ag50, HSA10-Ag50, and HSA20-Ag50 was measured in Dulbecco's Modified Eagle Medium up to 14 days. The results show that the cumulative release follows a similar trend for both type of supports, reaching values of about 12-14 $\mathrm{g}$ in the first 2 weeks (Figure 6). This amount corresponds to about $2 \mathrm{wt} \%$ of the initial Ag content of HA-Ag50, whereas the percentage of release from HSA containing samples is just about $1 \mathrm{wt} \%$ of the initial content.

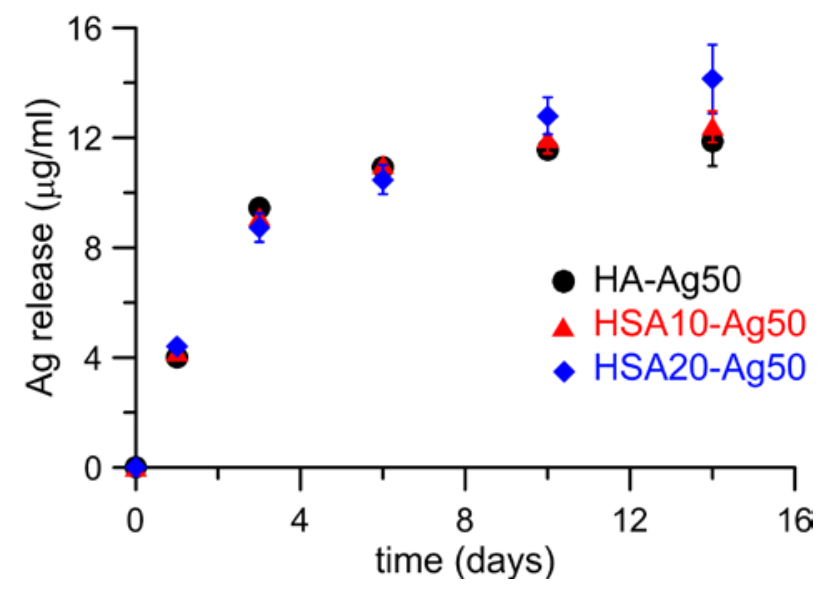

Figure 6. Silver cumulative release from HA-Ag50, HSA10-Ag50, and HSA20-Ag50 as a function of time.

At variance, the comparison of the thermogravimetric curves of the different samples before and after 14 days soaking in DMEM does not reveal significant difference in the total weight losses, in agreement with no significant hydroxystearate release from the samples (Figure 7). The results of Ag and hydroxystearate release are supported by the results of AFM analysis, which indicate that the 
morphology and the roughness parameters of the samples are not significantly affected by soaking in DMEM.

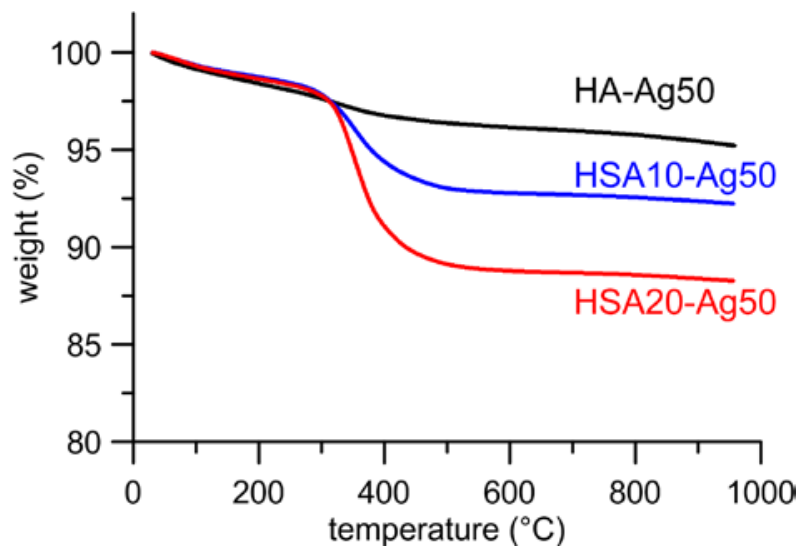

Figure 7. Thermogravimetric plots of HA-Ag50, HSA10-Ag50, and HSA20-Ag50 after 14 days soaking in DMEM.

\section{Conclusions}

The results of this study indicate that functionalization of hydroxyapatite nanocrystals with hydroxystearate enhances AgNPs loading, most likely thanks to the interaction between the positive charges provided by PEI on AgNPs and the negative charges of HSA. Loading increases as a function of hydroxystearate content reaching values up to $3.3 \mathrm{wt} \%$, without modifying nanocrystals' structural parameters, crystallinity, and morphology, which are influenced just by HSA content. Moreover, the good interaction with hydroxystearate functionalized hydroxyapatite crystals stabilizes AgNPs, which show a sustained release in solution.

Author Contributions: A.B., E.B., C.B. and M.C.C. conceived and designed the experiments; E.B., M.C.C. and K.R. performed the experiments; A.B., E.B., M.C.C. and K.R. analyzed the data; A.B., E.B., C.B. and M.C.C. contributed reagents/materials/analysis tools; A.B. and E.B. wrote the paper. All authors have read the final version of the manuscript.

Acknowledgments: This research was carried out with the financial support of the University of Bologna. The authors gratefully thank Gabriele Micheletti and Simon Sprocq for experimental support.

Conflicts of Interest: The authors declare no conflicts of interest.

\section{References}

1. Bigi, A.; Boanini, E. Functionalized biomimetic calcium phosphates for bone tissue repair. J. Appl. Biomater. Funct. Mater. 2017, 15, e313-e325. [CrossRef] [PubMed]

2. Capuccini, C.; Torricelli, P.; Boanini, E.; Gazzano, M.; Giardino, R.; Bigi, A. Interaction of Sr-doped hydroxyapatite nanocrystals with osteoclast and osteoblast-like cells. J. Biomed. Mater. Res. Part A 2009, 89A, 594-600. [CrossRef]

3. Lee, W.H.; Loo, C.Y.; Chrzanowski, W.; Rohanizadeh, R. Osteoblast response to the surface of amino acid-functionalized hydroxyapatite. J. Biomed. Mater. Res. Part A 2015, 103A, 2150-2160. [CrossRef] [PubMed]

4. Bose, S.; Tarafder, S. Calcium phosphate ceramic systems in growth factor and drug delivery for bone tissue engineering: A review. Acta Biomater. 2012, 8, 1401-1421. [CrossRef] [PubMed]

5. Verron, E.; Bouler, J.M.; Guicheux, J. Controlling the biological function of calcium phosphate bone substitutes with drugs. Acta Biomater. 2012, 8, 3541-3551. [CrossRef] [PubMed]

6. Kyllonen, L.; D’Este, M.; Alini, M.; Eglin, D. Local drug delivery for enhancing fracture healing in osteoporotic bone. Acta Biomater. 2015, 11, 412-434. [CrossRef] [PubMed] 
7. Bigi, A.; Boanini, E. Calcium phosphates as delivery systems for bisphosphonates. J. Funct. Biomater. 2018, 9, 6. [CrossRef] [PubMed]

8. Boanini, E.; Torricelli, P.; Boga, C.; Micheletti, G.; Cassani, M.C.; Fini, M.; Bigi, A. (9R)-9-Hydroxystearate-functionalized hydroxyapatite as antiproliferative and cytotoxic agent toward osteosarcoma cells. Langmuir 2016, 32, 188-194. [CrossRef] [PubMed]

9. Masotti, L.; Casali, E.; Gesmundo, N.; Sartor, G.; Galeotti, T.; Borrello, S.; Piretti, M.; Pagliuca, G. Lipid peroxidation in cancer cells: Chemical and physical studies. Ann. N. Y. Acad. Sci. 1988, 551, 47-58. [CrossRef] [PubMed]

10. Calonghi, N.; Pagnotta, E.; Parolin, C.; Molinari, C.; Boga, C.; Dal Piaz, F.; Brusa, G.L.; Santucci, M.A.; Masotti, L. Modulation of apoptotic signalling by 9-hydroxystearic acid in osteosarcoma cells. Biochim. Biophys. Acta Mol. Cell Biol. Lipids 2007, 1771, 139-146. [CrossRef] [PubMed]

11. Parolin, C.; Calonghi, N.; Presta, E.; Boga, C.; Caruana, P.; Naldi, M.; Andrisano, V.; Masotti, L.; Sartor, G. Mechanism and stereoselectivity of HDAC I inhibition by (R)-9-hydroxystearic acid in colon cancer. Biochim. Biophys. Acta Mol. Cell Biol. Lipids 2012, 1821, 1334-1340. [CrossRef] [PubMed]

12. Toy, W.; Macera, L. Evidence-based review of Silver dressing use on chronic wounds. J. Am. Acad. Nurse Pract. 2011, 23, 183-192. [CrossRef] [PubMed]

13. Rai, M.K.; Deshmukh, S.D.; Ingle, A.P.; Gade, A.K.J. Silver nanoparticles: The powerful nanoweapon against multidrug-resistant bacteria. Appl. Microbiol. 2012, 112, 841-852. [CrossRef] [PubMed]

14. Chernousova, S.; Epple, M. Silver as antibacterial agent: Ion, nanoparticle, and metal. Angew. Chem. Int. Ed. 2013, 52, 1636-1653. [CrossRef] [PubMed]

15. Chaloupka, K.; Malam, Y.; Seifalian, A.M. NanoSilver as a new generation of nanoproduct in biomedical applications. Trends Biotechnol. 2010, 28, 580-588. [CrossRef] [PubMed]

16. Gallo, J.; Holinka, M.; Moucha, C.S. Antibacterial surface treatment for orthopaedic implants. Int. J. Mol. Sci. 2014, 15, 13849-13880. [CrossRef] [PubMed]

17. Brennan, S.A.; Ní Fhoghlú, C.; Devitt, B.M.; O’Mahony, F.J.; Brabazon, D.; Walsh, A. Silver nanoparticles and their orthopaedic applications. Bone Joint J. 2015, 97-B, 582-589. [CrossRef] [PubMed]

18. Sivolella, S.; Stellini, E.; Brunello, G.; Gardin, C.; Ferroni, L.; Bressan, E.; Zavan, B. Silver Nanoparticles in Alveolar Bone Surgery Devices. J. Nanomater. 2012, 2012, 13.

19. Klug, H.P.; Alexander, L.E. X-ray Diffraction Procedures for Polycrystalline and Amorphous Materials; Wiley-Interscience: New York, NY, USA, 1974; ISBN 0471493694.

20. Bigi, A.; Boanini, E.; Gazzano, M.; Kojdecki, M.A.; Rubini, K. Microstructural investigation of hydroxyapatite-polyelectrolyte composites. J. Mater. Chem. 2004, 14, 274-279. [CrossRef]

21. Gonzalez-McQuire, R.; Chane-Ching, J.Y.; Vignaud, E.; Lebugle, A.; Mann, S. Synthesis and characterization of amino acid functionalized hydroxyapatite nanorods. J. Mater. Chem. 2004, 14, 2277-2281. [CrossRef]

22. Boanini, E.; Torricelli, P.; Cassani, M.C.; Gentilomi, G.A.; Ballarin, B.; Rubini, K.; Bonvicini, F.; Bigi, A. Cationic-anionic polyelectrolyte interaction as a tool to graft Silver nanoparticles on hydroxyapatite crystals and prevent cytotoxicity. RSC Adv. 2014, 4, 645-652. [CrossRef]

23. Boanini, E.; Torricelli, P.; Bonvicini, F.; Cassani, M.C.; Fini, M.; Gentilomi, G.A.; Bigi, A. A new multifunctionalized material against multi-drug resistant bacteria and abnormal osteoclast activity. Eur. J. Pharm. Biopharm. 2018, 127, 120-129. [CrossRef] [PubMed]

24. Yildirimer, L.; Thanh, N.T.K.; Loizidou, M.; Seifalian, A.M. Toxicological considerations of clinically applicable nanoparticles. Nano Today 2011, 6, 585-607. [CrossRef] [PubMed]

(C) 2018 by the authors. Licensee MDPI, Basel, Switzerland. This article is an open access article distributed under the terms and conditions of the Creative Commons Attribution (CC BY) license (http://creativecommons.org/licenses/by/4.0/). 